\title{
3 Follow the water in its high-subcritical state
}

\author{
Marie-Paule Bassez \\ Institut de Technologie, Université de Strasbourg, 67400 Illkirch-Graffenstaden, France; \\ marie-paule.bassez@unistra.fr, mpbassez@hotmail.com
}

\begin{abstract}
The expression "Follow the water" is used in order to recognize inside the universe, life as it exists on Earth. It is shown here that the expression "Follow the water in its high-subcritical state" can be used in order to recognize the components of life which form prior to the emergence of life. This specific state of water leaves signatures inside the minerals which are produced during highsubcritical water/rock interaction.
\end{abstract}

Keywords: anoxic iron oxidation; abiogenic ferric iron; high-subcritical water; alkaline; ferric oxides; ferric silicates; amorphous silica; origin of life; fluid inclusions; geobiotropy;

\section{Introduction}

Liquid water being an essential component of living organisms and of their environment, the strategy for the search for life in the universe is currently summarized in the expression "follow the water" which was chosen by NASA in the year circa 2000 as the new scientific approach for Mars exploration [1]. Recently I published an article which demonstrates that the specific state of water called high-subcritical has to be considered in the synthesis of molecules which constitute the living organisms and that it can be recognized in the evolution of the minerals [2]. After a study of liquid water [ 3 and refs herein] and envisioning that not only water in its liquid state, but water in its different states can be the appropriate medium to conduct chemical reactions which finally lead to biological molecules, I became interested in the structure of water under pressure and in the supercritical state [4-6] and I started to visualize rocks as reactants and not only as catalysts [6]. In 2008, I proposed experiments considering the rock peridotite or its constituents olivine and pyroxene, and the dissolution of apolar molecules in supercritical water [7]. Since 2013, I consider the state of water which is called high-subcritical and I present a new path for the synthesis of ferric minerals in anoxic conditions and for the concomitant chemistry which leads to macromolecules of life [8]. I conclude here in the present new article, that part of the search for life and its components can be specified in the expression "follow the water in its high-subcritical state". The interaction of water in this high-subcritical state and not above, with ferrous silicates containing rocks, produces ferric oxides, ferric silicates and molecular hydrogen, which form in anoxic conditions and at alkaline $\mathrm{pH}$. When water contains carbon dioxide and dinitrogen, macromolecules of amino-acids and components of life can form. Therefore, the observation of such ferric minerals with an anoxic origin can lead to the conclusion that molecules of life were possibly synthesized in a chemical path which 
was concomitant to the evolution of the rock and that I conceptualize with the term geobiotropy $[9$, 10].

\section{Methods and Materials}

As I show below in the paragraph on the third process, in the section 3, CO appears to be the essential starting molecule for the synthesis of biological molecules. While trying to answer the question "how CO is produced within the geological world?" I realized in 2009, that CO can be obtained from hydrogenation of $\mathrm{CO}_{2}$ not only in the gas phase, but also in high-subcritical water. The question became "how $\mathrm{H}_{2}$ is produced in high-subcritical water?" and in my role of a physical-chemist I conducted a bibliographical search for Pourbaix E-pH diagrams which could have been drawn for this state of water. In 2013, I presented my analysis of such diagrams [8]. The conclusion was that $\mathrm{H}_{2}$ and thus $\mathrm{CO}$ can form following the hydrolysis of the iron endmembers of olivine and pyroxene and also that ferric minerals can form without the presence of oxygen which is a breakthrough in the understanding of minerals which form in anoxic conditions as on Early Earth or extraterrestrial objects. In my OLEB'2018 article, I introduce in this context of the formation of ferric minerals, the analysis of diagrams drawn for the solubility of quartz, around the critical point of water. The present article is a summary of part of my precedent articles and presentations, with the goal of searching for life in the universe with the consideration of water in its high-subcritical state.

Therefore, the method is a logical association and composition of my theoretical analyses of diagrams which are based on experimental results and published by other scientists.

\section{Results and Discussions: Four processes in high-subcritical water}

Four processes which all occur in high-subcritical water contribute to produce both the ferric minerals which are observed in Archean rocks and the related geobiotropic molecules of life.

First, the oxidation of ferrous iron into ferric iron can occur at alkaline $\mathrm{pH}, 9.5$ to 14 , when water reaches temperatures $300^{\circ} \mathrm{C}-350^{\circ} \mathrm{C}$ and pressures $10-25 \mathrm{MPa}$. The combination of these values is called high-subcritical. They are below the supercritical point of water which has the values $374^{\circ} \mathrm{C}$ and 22.1 MPa for pure water. At these conditions, the density of water is ca $700-600 \mathrm{~kg} / \mathrm{m}^{3}$. I conclude in this possible chemical process through the analysis of Pourbaix diagrams which are drawn for the system Fe- $\mathrm{H}_{2} \mathrm{O}$ at $10^{-6}$ and $10^{-8} \mathrm{~mol} / \mathrm{kg}$ concentrations of dissolved ionic species, by W. Cook and $\mathrm{R}$. Olive in 2012 [11]. The calculations of the thermodynamic parameters used for these diagrams are based on the revised Helgeson-Kirkham-Flowers, R-HKF, model extended to water densities as low as $200 \mathrm{~kg} / \mathrm{m}^{3}$ [11 \& refs herein]. The Pourbaix diagrams which are drawn for supercritical water at $400^{\circ} \mathrm{C}, 25 \mathrm{MPa}, 10^{-6}, 10^{-8}$ and $10^{-11} \mathrm{~mol} / \mathrm{kg}$ of dissolved ionic species and $167 \mathrm{~kg} / \mathrm{m}^{3}$ density, does not show this ferrous oxidation.

Concomitant to the oxidation of iron in high-subcritical water, molecular hydrogen is released. In other words, the production of ferric iron in high-subcritical water and not above, does not require to consume oxygen, instead it is hydrogen which is produced.

Second, the solubility of $\mathrm{SiO}_{2}$ shows a turn-over at the critical point of water. Calculations based on the Fournier \& Potter 1982 equation show that at $23 \mathrm{MPa}$ "the $\mathrm{SiO}_{2}$ solubility increases to a value of $0.087 w t \%$ at $350^{\circ} \mathrm{C}$ and drastically decreases to $0.0081 w t \%$ at $450^{\circ} \mathrm{C}^{\prime \prime}$ as described by R. Smith and Z. Fang in 2011 [12 \& refs herein]. This abrupt change is observed in earlier diagrams for the solubility of quartz in water, drawn with experimental data and the R-HKF equations of state [13 \& refs herein]. 
High-subcritical water also controls the content in amorphous silica versus quartz. Indeed, as shown by P. Karasek et al. in 2013, at $23 \mathrm{MPa}$, the solubilities of amorphous and crystalline silica both increase with $\mathrm{T}$ with an abrupt decrease at the critical point. However, at the critical point of water, the solubility of amorphous silica appears to approximately double the solubility of quartz, while at $25^{\circ} \mathrm{C}$, the ratio of amorphous silica to quartz seems to be ca 18 [Fig. $3 \& 4$ in 14].

Third, the hydrogenation of $\mathrm{CO}_{2}$ by molecular hydrogen occurs not only in the gas phase as described by P. Sabatier in 1902 [15] but also in high-subcritical water, producing dissolved carbon monoxide, $\mathrm{CO}$, at $250^{\circ} \mathrm{C}-300^{\circ} \mathrm{C}$ and $25 \mathrm{MPa}$, as shown in the experiment conducted by Q. Fu and W. Seyfried in 2009 [16].

This CO is the necessary element in the synthesis of macromolecules of amino-acids in anoxic conditions, as observed by G. Schlesinger and S. Miller in 1983 [17] and by K. Kobayashi et al. in 1990 [18]. In the continuation of Kobayashi experiments, in 2004, Y. Takano irradiated, with $3 \mathrm{MeV}$ protons at room temperature, a gas mixture of 350 torr $\mathrm{CO}, 350$ torr $\mathrm{N}_{2}$ and 20 torr $\mathrm{H}_{2} \mathrm{O}$ provided by an under layer of liquid water [19]. A transmission electron microscopy, TEM, image of the dried irradiated products, scaled at $0.5 \mu \mathrm{m}$, shows aggregated particles [Fig.2 in 19]. "Following irradiation, products were recovered in $5 \mathrm{~mL}$ of pure water and subsequently freeze dried." The ca $0.3 \mathrm{mg}$ yellow-brown residue was pyrolyzed in helium at $765^{\circ} \mathrm{C}$ for $10 \mathrm{~s}$ and afterwards analyzed with GC-MS and SIM. The most intense peaks of the gas chromatogram correspond to urea $\left(\mathrm{NH}_{2}\right)_{2} \mathrm{CO}$, acetamide $\mathrm{CH}_{3} \mathrm{CONH}_{2}$, 2butanamine $\mathrm{C}_{2} \mathrm{H}_{5} \mathrm{CH}\left(\mathrm{NH}_{2}\right) \mathrm{CH}_{3}$, guanidine $\left(\mathrm{NH}_{2}\right)_{2} \mathrm{C}=\mathrm{NH}$, and to the branched cyclic compounds: dimethylpyrazine $\mathrm{C}_{6} \mathrm{H}_{8} \mathrm{~N}_{2}$, imidazole or pyrrazole $\mathrm{C}_{3} \mathrm{H}_{4} \mathrm{~N}_{2}$, 2-furanone $\mathrm{C}_{4} \mathrm{H}_{4} \mathrm{O}_{2}$, pyridinecarbonitrile $\mathrm{C}_{6} \mathrm{H}_{4} \mathrm{~N}_{2}$, ethenylpyridine $\mathrm{C}_{7} \mathrm{H}_{7} \mathrm{~N}$, $1 \mathrm{H}$-pyrrole-3-carbonitrile $\mathrm{C}_{5} \mathrm{H}_{4} \mathrm{~N}_{2}$, methylpyrimidine $\mathrm{C}_{5} \mathrm{H}_{6} \mathrm{~N}_{2}$, aniline? $\mathrm{C}_{6} \mathrm{H}_{7} \mathrm{~N}$, benzonitrile $\mathrm{C}_{6} \mathrm{H}_{5} \mathrm{CN}$, styrene $\mathrm{C}_{8} \mathrm{H}_{8} \ldots$ A list of 36 identified compounds is given by Takano et al. [19].

The same irradiation experiment was conducted in 2012 by Kurihara et al. [20]. An aqueous solution of the irradiated products was injected in a flow reactor at temperatures $150^{\circ}, 200^{\circ}, 250^{\circ}$, $300^{\circ}, 350^{\circ}, 400^{\circ} \mathrm{C}$ and $25 \mathrm{MPa}$ and quenched in cold water at $0^{\circ} \mathrm{C}$. Aggregates, $10 \mu \mathrm{m}$ in size, start to form at $200^{\circ} \mathrm{C}$ and are mainly observed at $250^{\circ} \mathrm{C}$ and above, with larger-sized aggregates at $300^{\circ} \mathrm{C}$ and above. For the $300^{\circ} \mathrm{C}$ products, the carbon X-ray absorption near-edge structure (XANES) and the nitrogen XANES spectra, recorded at the Lawrence Berkeley National Laboratory, show the peak of aromatic carbon and imine which do not appear for the room temperature product. Both $300^{\circ} \mathrm{C}$ and room temperature spectra show the peaks of nitrile, carbonyl in amide, carbonyl in ester, amide or amino groups.

In 2012, Y. Takano observed the dried yellow-brown irradiated products, with scanning electron microscopy, SEM, and atomic force microscopy, AFM. The SEM image, scaled at $1 \mu \mathrm{m}$, shows microand submicro-structures including filaments and aggregated spheres. Analyses were conducted on the hydrolyzed fraction obtained at ambient temperature. They show a great variety of amino-acids and a racemic mixture of $\mathrm{D}$, $\mathrm{L}$-alanine, which proves the absence of biotic contamination. The analysis is discussed by M.-P. Bassez in [21].

Carbon monoxide was also used in 2012 by S. Pizzarello in a mixture of $\mathrm{CO}, \mathrm{NH}_{3}$ and $\mathrm{H}_{2}$ at $370^{\circ} \mathrm{C}$ to synthesize amino-acids [22] and in 2003 by $\mathrm{H}$. Hill and J. Nuth in a mixture of $\mathrm{CO}, \mathrm{N}_{2}, \mathrm{H}_{2}$ at $300^{\circ} \mathrm{C}$ to synthesize precursors of amino-acids [23] as described in [2]. 
Therefore, organic functional groups which are necessary for the chemistry of the components of life are present in high-subcritical conditions, $300^{\circ} \mathrm{C} \& 25 \mathrm{MPa}$ as demonstrated by the above described experiments. Since fluid inclusions inside rocks are closed thermodynamic systems which permit the concentration of the molecules $\mathrm{H}_{2} \mathrm{O}, \mathrm{H}_{2}, \mathrm{CO}_{2}, \mathrm{~N}_{2}$ and their chemical reactions, I propose an hypothesis for the synthesis of the components of life as follows: when water is enclosed in the inclusion at high-subcritical conditions, $\mathrm{CO}$ can be synthesized. Macromolecules essential for the components of life can afterwards form, as described above, either with heat or through excitation with gamma rays from rocks which contain radioactive elements and which are located in the vicinity of the inclusion.

The fourth process to consider is the interaction of alkaline high-subcritical anoxic water with rocks which contain ferrous silicates. This interaction combines the three above processes. The oxidation of ferrous iron occurs with release of $\mathrm{H}_{2}$, and $\mathrm{SiO}_{2}$ dissolves. I show since 2013 that the rocks which contain ferrous silicates evolve in alkaline high-subcritical anoxic water and produce ferric minerals such as ferric trihydroxide, the ferric oxide hydroxides goethite and lepidocrocite, the ferric oxide hematite and ferric silicates such as greenalite. Minnesotaite is the iron analog of talc which forms by dehydration of the Mg-serpentine chrysotile in a solution supersaturated in silica. As talc, minnesotaite can form by dehydration of the Fe-serpentine greenalite in a solution supersaturated in silica. Since high-subcritical water dissolves easily silica, it can become saturated in silica and induce the dehydration of greenalite into minnesotaite. Stilpnomelane and riebeckite which contain much less $(-\mathrm{OH})$ groups than minnesotaite can most probably form also through further dehydration of greenalite. Thus, high-subcritical water appears to be the adequate medium to produce ferric oxides hydroxides, ferric oxides, ferric silicates, amorphous silica and quartz with a ratio of amorphous silica/quartz up to 2 . The concomitant production of $\mathrm{H}_{2}$ can be used to form $\mathrm{CO}$ and components of life as in the third process.

Therefore, the state of water which is basic ( $\mathrm{pH} \sim 9.5-14)$ and high-subcritical $\left(300{ }^{\circ} \mathrm{C}-350{ }^{\circ} \mathrm{C}, 10\right.$ $25 \mathrm{MPa}$ ) appears to permit the transformation of the rocks which contain ferrous iron, into ferric minerals and associated biological molecules. Anoxic alkaline water in its high-subcritical state seems to be an essential component for the synthesis of ferric minerals in anoxic conditions and to the concomitant synthesis of components of life inside fluid inclusions located within the rocks. It is important to notice that this process occurs in the absence of oxygen. The above described four chemical processes are summarized in the concept of geobiotropy which is visualized in Fig.1 and which leads to the expression "Follow the water in its high-subcritical sate". Indeed, water has to be followed in order to recognize, in the universe, life as it exists on Earth, and water in its highsubcritical state has to be followed in order to recognize the components of life which form prior to the emergence of life. 


\section{$300^{\circ}-350^{\circ} \mathrm{C} \quad 10-25 \mathrm{MPa}$}

\section{Follow the water in its high-subcritical state}

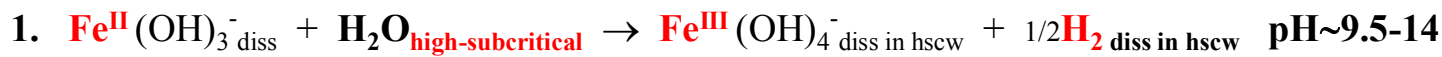
no $\mathrm{Fe}^{\mathrm{III}}$ above $\mathrm{Tc}\left(374^{\circ} \mathrm{C}, 22.1 \mathrm{MPa}\right)$

2. $3 \mathrm{SiO}_{2 \text { quartz }} \rightarrow \mathrm{SiO}_{2 \text { diss quartz }}+\sim 2 \mathrm{SiO}_{2}$ amorph (Shock et al.1989) (Smith\&Fang 2011) (Karasek et al. 2013) no $\mathrm{SiO}_{2 \text { diss }}$ above Tc

3. $\mathrm{CO}_{2 \text { diss }}+\mathrm{H}_{2 \text { diss }} \rightarrow \mathrm{CO}_{\text {diss }}+\mathrm{CH}_{4 \text { diss }} \quad 250^{\circ}-300^{\circ} \mathrm{C}, 25 \mathrm{MPa}$, catalyst: $\mathrm{Fe}_{3} \mathrm{O}_{4} \quad$ (Fu \& Seyfried 2009)

4. $\mathrm{Fe}_{2} \mathrm{SiO}_{4(\mathrm{~s})}+\mathrm{H}_{2} \mathrm{O}_{\text {(hsc) }} \rightarrow \mathrm{SiO}_{2 \text { diss } \mathrm{Q}}+\mathrm{SiO}_{2 \text { amorph silica }}$

$\rightarrow$ Ferric oxides: goethite, hematite $++\mathbf{H}_{2 \text { (diss in hscw) }}$

$\rightarrow$ Ferric silicates: greenalite $\left(\mathrm{Fe}^{\mathrm{II}}, \mathrm{Fe}^{\mathrm{III}}\right)_{2-3} \mathrm{Si}_{2} \mathrm{O}_{5}(\mathrm{OH})_{4}$ minnesotaite $\left(\mathrm{Fe}_{3}{ }_{3}, \mathrm{Fe}^{\mathrm{III}}{ }_{2}\right) \mathrm{Si}_{4} \mathrm{O}_{10}(\mathrm{OH})_{2}$

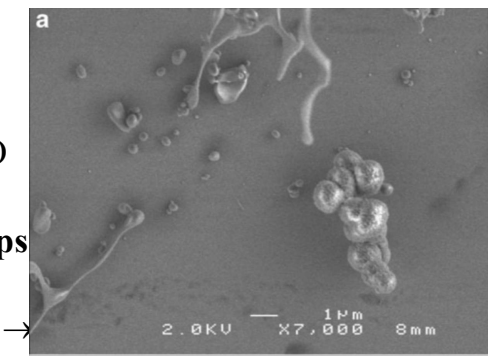

Figure 1. The concept of geobiotropy which represents the transformation of ferrous silicates containing rocks in alkaline high-subcritical anoxic water, for the production of ferric minerals and macromolecules of aminoacids. The equations show the dissolved products, but are not all equilibrated.

\section{Conclusion}

With the four chemical processes described above, I try to demonstrate that the specific state of water which is called high-subcritical leaves signatures inside the minerals which are produced during high-subcritical water/rock interaction. In other words, the interaction of alkaline high-subcritical anoxic water with rocks which contain ferrous silicates composes a mineralogy and biology oeuvre for the synthesis of ferric minerals and components of life. From the numbers emerges the form. Observations of these mineral signatures inside rocks, lead to the conclusion that components of life may have formed at that location, thus preceding the emergence of life.

Acknowledgments: At the EANA'2018 conference, 24-28 September 2018 in Berlin, I had the opportunity to give an oral presentation from which this article is issued. I sincerely like to express my kind recognition to Professor Lena Noack, Free University Berlin, Germany and to the organizing committee. I am also grateful to Dr. Alan Schwartz, editor-in-chief of the journal Origins of Life and Evolution of the Biospheres, for his advises concerning the figure.

184 Funding: This research was funded with an FDSP grant

185 Conflicts of Interest: The author declares no conflict of interest

\section{References}

1. Hubbard, S.G.; Naderi, F.M. \& Garvin, J.B. Following the water, the new program for Mars exploration. Acta Astronautica 2002, 51(1-9), 337-350. https://doi.org/10.1016/S0094-5765(02)00067-X

2. Bassez, M.-P. Water near its supercritical point and at alkaline $\mathrm{pH}$ for the production of ferric oxides and silicates in anoxic conditions. A new hypothesis for the synthesis of minerals observed in Banded Iron 
Formations and for the related geobiotropic chemistry inside fluid inclusions. Orig Life Evol Biosph 2018 open on-line 08 August https://doi.org/10.1007/s11084-018-9560-y

3. Bassez, M.-P.; Lee, J.; Robinson, G.W. Is liquid water really anomalous? J. Physical Chemistry 1987, 91, 58185825. DOI: $10.1021 / j 100306 a 060$

4. Witzel, T.; Director: Bassez, M.-P. Etude bibliographique de l'eau supercritique. Rapport de stage, 1èreannée, IUT-Chimie, Université Robert Schuman, Strasbourg, Fr, 1997.

5. Bassez, M.-P. La structure de l'eau supercritique et l'origine de la vie. In: Sciences et Technologies: regards croisés sciences pour l'ingénieur, informatique, mathématiques, biologie, biochimie, chimie. L'Harmattan ed., ISBN 2-7384-7367-9, 1999, p. 583-591.

6. Bassez, M.-P. Is high-pressure water the cradle of life? J. Phys. Condens Matter, 2003, 15(24), L353-L361. doi.org/10.1088/0953-8984/15/24/101

7. Bassez, M.-P. Prebiotic synthesis under hydrothermal conditions. C. R. Chimie, Académie des Sciences, Paris, 2009, 12 (6-7), 801-807, on-line Dec.5th 2008. doi: 10.1016/j.crci.2008.10.013

8. Bassez, M.-P. Geochemical origin of biological molecules. European Geosciences Union, EGU'2013, Vienna, Austria; Session: Planetary \& Solar System Sciences/Origins \& Astrobiology/Planetary Evolution \& Life/PS8.1; Oral: Tues. April 9th/9h30/EGU2013-22. Geophysical Research Abstract\#2013, Vol.15, EGU2013-22, 2013. http://meetingorganizer.copernicus.org/EGU2013/EGU2013-22.pdf open

9. Bassez, M.-P. Geobiotropy. Lunar \& Planetary Science Conference, LPSC'2016, The Woodlands, U.S. Exobiology/Abstr\#1853, 2016. http://www.hou.usra. edu/meetings/lpsc2016/pdf/session804.pdf open

10. Bassez, M.-P. Anoxic and oxic oxidation of rocks containing Fe(II)Mg-silicates and Fe(II)-monosulfides as source of Fe(III)-minerals and hydrogen. Geobiotropy. Orig Life Evol Biosph 2017, 47, 453-480. doi: 10.1007/s11084-018-9560-y

11. Cook, G.W.; Olive, P.R. Pourbaix diagrams for the iron-water system extended to high \& low supercritical conditions. Corros. Sci. 2012, 55, 326-331. doi:10.1016/j.corsci.2011.10.034

12. Smith, R.L. Jr; Fang, Z. Properties and phase equilibria of fluid mixtures as the basis for developing green chemical processes. Fluid Phase Equilib. 2011, 302, 65-73. doi:10.1016/j.fluid.2010.09.030

13. Shock, E.L.; Helgeson, H.C.; Sverjensky, D.A. Calculation of the thermodynamic and transport properties of aqueous species at high pressures and temperatures: standard partial molal properties of inorganic neutral species. Geochim. Cosmochim. Acta 1989, 53, 2157-2183.

14. Karasek, P.; Stavikova, L.; Planeta, J.; Hohnova, B.; Roth, M. Solubility of fused silica in sub- and supercritical water: estimation from a thermodynamic model. J. Supercrit. Fluids 2013, 83, 72-77. http://dx.doi.org/10.1016/j.supflu.2013.08.012

15. Sabatier, P.; Senderens, J.B. Hydrogénation directe des oxydes du carbone en présence de divers métaux divisés. Comptes rendus des séances hebdomadaires de l'académie des sciences 1902, 134, 689-691.

16. Fu, Q.; Seyfried, Jr W.E. Experimental study of abiotic synthesis processes in a hydrothermal flow system. LPSC'2009, 23 March 2009/10h45. The Woodlands, U.S., Astrobiology/Abstr \#2504. https://www.lpi.usra.edu/meetings/lpsc2009/pdf/sess104.pdf open

17. Schlesinger, G.; Miller, S.L. Prebiotic synthesis in atmospheres containing $\mathrm{CH}_{4}, \mathrm{CO}$, and $\mathrm{CO}_{2}$. J. Mol. Evol. 1983, 19, 376-382.

18. Kobayashi, K.; Tsuchiya, M.; Oshima, T.; Yanagawa, H. Abiotic synthesis of amino acids and imidazole by proton irradiation of simulated primitive earth atmospheres. Orig. Life Evol. Biosph. 1990, 20, 99-109.

19. Takano, Y.; Marumo, K.; Yabashi, S.; Kaneko, T.; Kobayashi, K. Pyrolysis of complex organics following high-energy proton irradiation of a simple inorganic gas mixture. Applied Physics Letters 2004, 85(9), 16331635. doi: $10.1063 / 1.1785858$ 
235 20. Kurihara, H.; Yabuta, H., Kaneko, T.; Obayashi, Y.; Takano, Y.; Kobayashi, K. Characterisation of organic aggregates formed by heating products of simulated primitive Earth atmosphere experiments. Chem. Lett. 2012, 41, 441-443. doi:10.1246/cl.2012.441

238 21. Bassez, M.-P.; Takano, Y.; Kobayashi, K. Prebiotic organic microstructures. Orig. Life Evol. Biosph. 2012, 42(4), 307-316. doi: 10.1007/s11084-012-9290-5

22. Pizzarello, S. Catalytic syntheses of amino acids and their significance for nebular and planetary chemistry. Meteorit. Planet Sci. 2012, 47(8), 1291-1296. doi: 10.1111/j.1945-5100.2012.01390.x

23. Hill, H.G.M.; Nuth, J. The catalytic potential of cosmic dust: implications for prebiotic chemistry in the solar nebula and other protoplanetary systems. Astrobiology 2003, 3(2), 291-304. 